the excited brain and calming the disturbed system, so that the patient may fall into a refreshing slumber, in which state alone the nutrition of the organ can be restored? Nature may be thus assisted by the judicious use of calmatives to allay irritation and diminish rest. lessness; and it is in this way that opium and digitalis may be usefully employed. I believe there is great danger in the old and empirical practice of pushing remedies until artificial sleep or a state of narcotism is induced; and that this ought to be the simple principle of our treatment-to remove, as far as possible, any pal. pable derangement of the system, and promote tranquillity of mind and body, so that the patient may sleep to recover.

\section{"RED VULCANITE" IN DENTISTRY.}

By Edward Wells, M.D., F.R.C.P., Reading.

[Read before the Reading Pathological Society.]

REv. Mr. C. being, as he considered, in perfect health, went about six weeks back to a dentist in London, who fitted him with a frame containing upper and lower teeth. Immediately upon wearing them, he found a metallic taste in his mouth, which was very disagreeable. By degrees, his health began to fail; he became weak and nervous, lost his appetite, and began to emaciate; had flatulency, fœtid breath, and looseness of bowels.

After wearing the teeth for six weeks, he became con. vinced that they were the cause of his ailments; that he was, in fact, being slowly poisoned.

This led him to send for me. I found him suffering from nervous prostration. Pulse 100, weals; tongue coated with a white film; the urine was whey-like, having an extremely fotid odour, faintly acid; specific gravity 1009 , slightly albuminous on boiling.

On examining the teeth, which are exhibited, the basis is found to be what is termed "red vulcanite", a compo. sition, as I learn, of vermilion, sulphur, and India. rubber, vulcanised. This composition, therefore, contains the red sulphuret of mercury, probably to some amount, as the colour is entirely due to that salt.

Now, as the "red vulcanite" is largely used in den. tistry, it is possible that it may not so rapidly affect many persons as it did my patient; for Mr. C. is peculiarly sensitive to the action of mercury. When ill, he is never able to take the least mercurial medicine without experiencing its toxic effects. This is probably due to his being predisposed to an affection of the kidneys. He was therefore peculiarly susceptible of the poisonous effects of the vermilion contained in the basis; and, from the condition of the urine, I think there is no doubt he was suffering from the injurious impression made by the mercury on the urinary organs. It is not improbable that there may have already existed some disease of the kidney in a latent form, which has been called into action by the absorption of the mineral. Such an explanation of his symptoms, however, would not render the use of such a basis-in his case, at least, as well as in many others-a whit the less objectionable.

In the short time that has elapsed since leaving off the teeth, he has become gradually better and stronger. The urine is much less fotid; the appetite has improved; and the tongue is cleaner. The improvement has been sufficient to leave him still fully convinced that the teeth were the cause of his illness.

I have ventured to bring this case before you, as in consequence of its great adaptability to the mouth, the "red vulcanite" is largely used, and it is possible you may be called to cases in which it is acting injuriously on the system, but in which the patient has failed to discover the cause, and in which it may fall upon the medical attendant to diagnose the causa mali.

P.S. The urine has since risen to specific gravity 1020.

\section{Cramsactions of 速xamebes.}

\section{SOUTH MIDLAND AND CAMBRIDGE AND HUNTINGDON BRANCHES.}

ON GAOI.DIETS, AND ON THAT OF THE HUNTINGDON GAOI. in PARTICULAR.

By M. Foster, Esq.; Huntingdon.

[Read at Peterborough, July 9th, 1863.]

InCIDENTALLY to the great question of How to Treat our Criminals, much has been said and written about the way in which they are fed. The popular opinion seems to be that the inmates of our gaols live in the enjoyment of a better diet than that of our paupers and our agricultural poor. Having been a gaol-surgeon for now nearly thirty years, I feel justified in bringing the subject before my medical brethren; and wish first to examine briefly and critically our present gaol-diets, and theu to relate a little of my experience of the past.

But, first of all, a few words must be said on what a gaol-diet ought to be. The law assumes, and therefore we need not argue the point, that the prisoners ought not to suffer in health through their imprisonment. They must, then, have enough proper food to keep them in health. They do, or rather they ought to, go through a great deal of hard labour. They ought, therefore, to have a quantity of ingesta sufficient to cover the ensuing bodily waste. The influence of the prison is depressing, and most probably lowers the assimilative powers of the body. Their diet, therefore, should be rather in excess of what would be required under other circumstances. The food should be presented in a digestible form; but everything that merely pleases the palate should be avoided. Monotony, on the other hand, inasmuch as it impairs digestion and assimilation, should be shunned. Lastly, the material should be as cheap as possible, consistently with other requirements. In fine, if we con. sider the prisoners as so many persons to be trained in the easiest and most economical manner for the purpose of undergoing prison-labour, we shall put ourselves in the best position for estimating the value of the various diets suggested for their use.

I purpose in the present paper to consider only the case of prisoners of long sentences; i.e., of above three months imprisonment with hard labour; for it is in connection chiefly with these that any interest is attached to the question of diet; and though making references to other gaols, I shall speak mostly of the Huntingdon County Gaol, with which I am particularly connected.

Let us compare the diet, then, of such prisoners as these with the daily food of other classes.

It is impossible, with our present knowledge, to lay down an incontrovertible standard diet. The best, perhaps, of such standard diets as have been proposed, is that of Moleschott, who says that the standard man should consume within twenty-four hours, of nitrogenous material, $4 \frac{1}{2}$ ounces; of starch and sugar, $14 \frac{1}{2}$ ounces; of fat, $3 \frac{1}{2}$ ounces. This will provide about 300 grains of nitrogen, corresponding to about 600 grains of urea, and about nine ounces of carbon-thus supplying the standard daily waste and allowing a surplus for loss, etc. The dietaries of soldiers and sailors correspond very closely with this.

Our well-to-do classes consume, perhaps, more than this, especially of the nitrogenous elements. I found that a young man, aged 27 , weighing between eleven and twelve stone, of active employment, consumed, of nitrogenous matter, 5 ounces; starch and sugar, 13 ounces; fat, 4 ounces. 